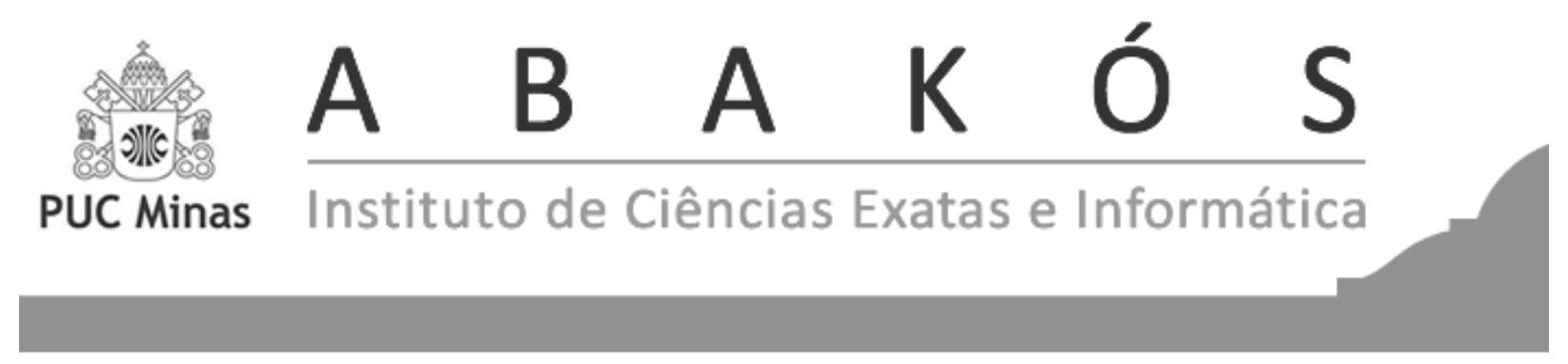

c) (1)

\title{
Estudo dos Números Reais em um Curso de Análise sob a Perspectiva Investigativa da História da Matemática*
}

Study of the Real Numbers in a Course of Analysis under the Investigative Perspective of the

History of Mathematics

Kelly Roberta Mazzutti Lübeck ${ }^{1}$

\begin{abstract}
Resumo
Este artigo apresenta a pesquisa desenvolvida junto a uma turma do quarto ano do curso de Licenciatura em Matemática, na disciplina de Análise Real, que se propôs a discutir a formalização dos conjuntos numéricos sob a perspectiva investigativa da História da Matemática. A metodologia de pesquisa utilizada foi a pesquisa-ação e o trabalho teve como objetivos conduzir os acadêmicos a uma possível compreensão da estrutura dos números reais e, consequentemente, da sua importância à fundamentação de conceitos relativos à disciplina através de incursões históricas e, concomitantemente, avaliar a postura destes futuros professores frente às situações investigativas. Além de oferecer uma forma alternativa de se trabalhar determinados conceitos da Análise, pode-se dizer que as discussões que se sucederam foram relevantes à formação de futuros professores que ensinarão Matemática e os resultados da investigação, segundo avaliação dos atores do processo, levaram-nos ao entendimento de que o uso da História favoreceu o processo de aprendizagem relativo aos temas abordados, bem como motivou os alunos a refletirem sobre o papel da Análise na grade curricular e em sua formação.
\end{abstract}

Palavras-chave: História da Matemática. Análise real. Números reais. Ensino. Aprendizagem.

* Submetido em 02/04/2019 - Aceito em 21/09/2020

${ }^{1}$ Professora Doutora do curso de Licenciatura em Matemática da Universidade Estadual do Oeste do Paraná UNIOESTE e colaboradora do Programa de Pós-Graduação em Ensino - PPGEn, campus de Foz do Iguaçu/ PR, Brasil - kelly.lubeck@unioeste.br ou kellyrobertaml@gmail.com 


\begin{abstract}
This paper presents an investigation carried out with a group of students in the fourth year of Mathematics, through the discussion of formalization of numerical sets in Real Analysis, under the History of Mathematics investigative perspective. By using the Research-Action methodology, the work aimed to lead students to a possible understanding of the structure of real numbers and, consequently, of its importance for the (theoretical) foundation of the concepts related to the subject through historical incursions. We also, concomitantly, evaluate the posture of these future teachers in investigative situations. Besides presenting an alternative way of working certain concepts of Analysis, we realize that the subsequent discussions were relevant to the formation of future Mathematics teachers. According to the evaluation of the actors involved in the process, the use of History of Mathematics favored the learning process, as well as motivated them to think about the role of Analysis in the curriculum and, in their formation.
\end{abstract}

Keywords: History of Mathematics. Real analysis. Real numbers. Teaching. Learning. 


\section{INTRODUÇÃO}

A preocupação com o entendimento adequado e a produção de significados relativos aos conteúdos, acompanha os formadores, isto porque se espera que os acadêmicos desenvolvam habilidades possíveis, em relação à produção de conhecimento para exercerem suas funções de educadores. Logo, repensar a maneira de apresentar as disciplinas, ou seja, pensar em novas abordagens metodológicas é um exercício constante, em especial à formação de licenciados em Matemática que muitas vezes carregam o estigma de uma disciplina difícil, tediosa. Neste sentido, concorda-se com a ideia de Mendes (2009) quando este afirma que

As abordagens a serem efetivadas no contexto universitário de ensino devem ter como meta principal fomentar a aquisição da educação científica pelos estudantes. É necessário, porém, que os professores proponham e efetivem atividades formativas permeadas por estratégias didáticas que estimulem o espírito investigador dos estudantes, de modo a articular a pesquisa à formação do futuro professor pesquisador (p. 102).

[...] Trata-se, porém, de um exercício da investigação científica com objetivos didáticos, visto ter como principal alvo a aprendizagem matemática do estudante. Todavia, há um princípio norteador dessa aprendizagem que é decisivamente formativo: a pesquisa como princípio educativo (p. 103).

Outra questão que se associa à disciplina de Matemática, e que faz refletir sobre a forma que ela é trabalhada, diz respeito ao uso exagerado de fórmulas e resultados, muitas vezes sem uma adequada interpretação, ou seja, associa-se a ela um status de conjunto de regras, exibido previamente para solucionar determinados problemas. Esta visão equivocada pode ser redimida quando apresentado o processo de construção de seus conceitos; isto é, quando se mostra que a Matemática está em constante desenvolvimento, que ela surge de diversos processos da construção humana, num contínuo refletir. Ademais,

[...] todo conteúdo de saber é resultado de um processo de construção de conhecimento. Por isso, dominar conhecimentos não se refere apenas à apropriação de dados objetivos pré-elaborados, produtos prontos do saber acumulado. Mais do que dominar os produtos, interessa que os alunos compreendam que estes são resultantes de um processo de investigação humana (PIMENTA; ANASTASIOU, 2014, p. 17).

É necessário, também, rever as práticas frente às dificuldades dos acadêmicos. Muitos não compreendem conceitos ditos básicos, entram no curso com tais lacunas e, por vezes, a carregam durante toda a sua graduação. A Análise, neste seu repensar minucioso do conteúdo matemático, pode contribuir para sanar tais obstáculos, à medida que explora uma Matemática formal e, por assim dizer, precisa, do ponto de vista da Matemática acadêmica. Essa disciplina pretende esmiuçar conceitos que dão embasamento à teoria do Cálculo Diferencial e Integral, abrindo um leque de possibilidades de investigação. Logo, é possível neste espaço lançar mão 
de processos rigorosos para discutir dúvidas dos alunos, muitas vezes vinculadas ao conjunto dos números reais e suas operações, aos processos de simplificações, propriedades de potenciação (real), convergência de sequências e séries, dentre outros assuntos.

Assim, esse artigo expõe o trabalho desenvolvido junto a uma turma de Análise Real, disciplina do curso de Licenciatura em Matemática, na qual se buscou inserir o uso da História da Matemática para se trabalhar com a conceituação, formalização e utilização correta das propriedades dos conjuntos numéricos e as implicações destas para os conteúdos subsequentes desta disciplina. A escolha da Análise se deu por dois motivos. O primeiro por se tratar de uma matéria que faz o "fechamento" das ideias do Cálculo Diferencial e Integral que são apresentadas nos primeiros semestres dos cursos de Matemática e que necessitam de conhecimentos e raciocínios que os acadêmicos ingressantes teriam dificuldades de acompanhar, ou seja, ela encerra um ciclo de estudos a respeito de um tema que revolucionou o mundo científico - o Cálculo. De fato, os conceitos do Cálculo "têm tanto alcance e tantas implicações no mundo moderno que talvez seja correto dizer que sem algum conhecimento deles dificilmente hoje uma pessoa poderia considerar-se culta" (EVES, 2004, p. 417).

Já o segundo motivo se refere ao ano em que se desenvolve a pesquisa, quarto - e último - ano do curso, na tentativa de se avaliar a postura destes futuros professores frente às situações investigativas propostas, pois

trabalhar o conhecimento no processo formativo dos alunos significa proceder à mediação entre os significados do saber no mundo atual e aqueles dos contextos nos quais foram produzidos. Significa explicar os nexos entre a atividade de pesquisa e seus resultados, portanto, instrumentalizar os alunos no próprio processo de pesquisar (PIMENTA; ANASTASIOU, 2014, p. 17).

Na sequência, serão abordados os aspectos metodológicos da pesquisa, que se apoiaram nos pressupostos da pesquisa-ação e do trabalho colaborativo, considerando que

A pesquisa-ação é um tipo de pesquisa social que é concebida e realizada em estreita associação com uma ação ou com a resolução de um problema coletivo e no qual os pesquisadores e os participantes representativos da situação da realidade a ser investigada estão envolvidos de modo cooperativo e participativo (THIOLLENT, 1985, p. 14).

Também, serão apresentadas as ações desenvolvidas com os acadêmicos e as análises de como isto beneficiou o ensino e a aprendizagem dos conteúdos trabalhados. Ademais, neste desenrolar, far-se-á uma discussão sobre o impacto da História como uso metodológico e de como isto influenciou o aprendizado dos temas.

\section{DESENVOLVIMENTO}

O curso de Análise Real que trata, entre outras coisas, da fundamentação de vários conceitos do Cálculo Diferencial e Integral, é uma disciplina dita como complexa pelos alunos e, de 
certa forma, por abordar muitas demonstrações e requerer a utilização de uma linguagem matemática extremamente formal ela acaba por apresentar certas dificuldades. Logo, faz sentido investigar novas maneiras de se trabalhar os seus conteúdos. Conforme Baroni e Otero-Garcia (2013) "A disciplina de análise, é, em geral, tida como geradora de grande ansiedade nos alunos [...] sendo que o formalismo e abstração presentes em sua estrutura causa forte impacto e o índice de reprovação costuma ser alto" (p. 9), o que reforça a ideia de ampliar as discussões sobre as metodologias utilizadas nestes cursos, bem como o material de apoio. Ademais, conforme Katz (2010), a formalização de seus conceitos é relativamente recente, se estabeleceram em meados do século XIX com os trabalhos de Cauchy (1789 - 1857), Weierstrass (1815 - 1897), Cantor (1845 - 1918) etc., podendo justificar, de certa forma, porque os alunos têm bastante dificuldade com estes pontos. Outrossim, a preocupação com os processos infinitos e com detalhes que os pesquisadores até então não enfatizavam em seus trabalhos passaram a ser considerados, estabelecendo-se uma nova classe de saberes que, por vezes, não foi bem recebida pela comunidade científica.

A dificuldade encontrada em se aceitar os novos métodos advinha não só da própria dificuldade em trabalhar com eles (alguns matemáticos prodigiosos, como Joseph Liouville (1809-1882) relatavam não conseguir entender os argumentos empregados), e eventualmente do conservadorismo, como também da necessidade que esses métodos criaram de se rever antigos resultados que há muito eram considerados corretos. (BARONI; OTERO-GARCIA, 2013, p. 64-65).

Percebe-se, com isto, que os métodos impetrados na disciplina de Análise Real podem causar certa resistência, mas que pode ser exaurida se, ao invés de se trabalhar puramente com as técnicas, se discutir a motivação que levou o estabelecimento de tais resultados e, neste ponto, o uso da História da Matemática pode contribuir significativamente. De fato,

A investigação histórica como um processo didático nas aulas de matemática pode contribuir para que os estudantes se familiarizem com o uso de referências bibliográficas na compreensão do desenvolvimento históricoepistemológico da matemática, além de ganharem autonomia para trabalharem de maneira independente na construção de sua própria aprendizagem (MENDES, 2015, p. 274).

A História ajuda a esclarecer os porquês das coisas, a estabelecer os nexos de resultados que, por vezes, são ostentados como 'presentes divinos' que estabelecem uma verdade genuína. Além do mais, o emprego da História da Matemática pode levar o aluno a perceber

(1) A matemática como uma criação humana; (2) as razões pelas quais as pessoas fazem matemática; (3) as necessidades práticas, sociais, econômicas e físicas que servem de estímulo ao desenvolvimento das ideias matemáticas; (4) as conexões existentes entre matemática e filosofia, matemática e religião, matemática e lógica, etc.; (5) a curiosidade estritamente intelectual que pode levar à generalização e extensão de ideias e teorias (MIGUEL; MIORIM, 2004, p. 53). 
Por se tratar de uma pesquisa em que o campo de investigação está diretamente ligado ao investigante, uma vez que a disciplina de Análise foi ministrada pela pesquisadora em questão, o método escolhido para o trabalho foi a pesquisa-ação. Isto por que

A pesquisa-ação é um tipo especial de pesquisa participante, em que o pesquisador se introduz no ambiente a ser estudado não só para observá-lo e compreendê-lo, mas sobretudo para mudá-lo em direções que permitam a melhoria das práticas e a melhor liberdade de ação e de aprendizagem dos participantes (FIORENTINI; LORENZATO, 2006, p. 112).

Assim, acreditando também que numa pesquisa qualitativa o pesquisador "não se abriga em uma posição de neutralidade científica, pois está implicado necessariamente nos fenômenos que conhece e nas consequências desse conhecimento que ajudou a estabelecer" (LUDKE; ANDRÉ, 1986, p. 5), optou-se por realizar o estudo nestes moldes.

É importante destacar que a análise dos diferentes dados, narrativas e observações, obtidos no decorrer das etapas de investigação, inspirou-se na análise textual discursiva, já que a "principal característica da Análise Textual Discursiva [...] no que concerne à descrição e à interpretação na análise, está a acepção de desenvolver ambos os elementos de modo integrado" (MEDEIROS; AMORIM, 2017, p. 250). Ainda,

O envolvimento com a análise textual discursiva implica ruptura com o paradigma dominante de ciência, fundamentado em suposta verdade, objetividade e neutralidade. Nesse tipo de análise exige-se do pesquisador mergulhar em seu objeto de pesquisa, assumindo-se sujeito e assumindo suas próprias interpretações. Nesse movimento hermenêutico são solicitadas constantes retomadas do concretizado, visando a permanente qualificação dos resultados. (MORAES; GALIAZZI, 2006, p. 122).

Deste modo, a análise textual discursiva permite maior flexibilização metodológica na interpretação dos dados e, consequentemente, auxilia o investigador a refletir sobre perspectivas antes não cogitadas. Neste sentido,

Outro ponto importante nesta etapa é a consideração tanto do conteúdo manifesto quanto do conteúdo latente do material. É preciso que a análise não se restrinja ao que está explícito no material, mas procure ir mais a fundo, desvendando mensagens implícitas, dimensões contraditórias e temas sistematicamente “silenciados". (LUDKE; ANDRÉ, 1986, p. 48)

Para decidir o tema da disciplina de Análise que seria trabalhado, levou-se em consideração um ponto central do curso, o eixo norteador de várias demonstrações, que recai essencialmente sobre a reta real, ou formalmente falando, sobre o corpo ordenado completo dos números reais (IR). De fato, olhando de uma forma geral para os conteúdos abordados nos cursos de Cálculo e Análise é pertinente observar que 
O que uma derivada realmente é? Resposta: um limite.

O que uma integral realmente é? Resposta: um limite.

O que uma série infinita al $+a 2+a 3+\ldots$ realmente é? Resposta: um limite. Isto nos leva a:

O que é um limite? Resposta: um número.

E finalmente a última questão:

O que é um número? (HAIRER; WANNER, 2008, p. 170-171, tradução dessa auditoria)

O que a citação resume, de uma maneira simplista, e os resultados de Análise legitimam, é que a estruturação dos conjuntos numéricos é fundamental para o desenrolar do curso. Ainda, conforme Eves (2004) "pode-se afirmar hoje que, essencialmente, a consistência de toda a matemática existente dependa da consistência do sistema dos números reais. Nisso reside a tremenda importância do sistema dos números reais para os fundamentos da matemática” (p. 611).

Portanto, é plausível a pergunta: Como trabalhar com a formalização da existência de um corpo ordenado completo sem demonstrar esta questão? Isso porque num curso de Análise, numa licenciatura, não se tem tempo para realizar tal construção e nem é um dos objetivos para a formação do licenciando.

Uma maneira muito interessante de contornar tal fato é investigar os contextos históricos em que problemas que envolvem a numeração foram surgindo e discutir com os acadêmicos as implicações disto.

A História da Matemática como ferramenta metodológica passou a ser utilizada e fomentada há alguns anos e pesquisadores apontam tal recurso como um facilitador à aprendizagem, além de poder motivar o aluno, explicar as causas das produções científicas e justificar a evolução das ideias como produção do conhecimento humano. "Além do mais, a partir do significado histórico e conceitual dos tópicos básicos da Matemática, é possível conduzir os alunos para que eles possam construir sua aprendizagem através de atividades investigatórias desenvolvidas em sala de aula" (MENDES, 2009, p. 183).

Assim, optou-se por dividir a tarefa em três etapas, as quais estão descritas abaixo.

Primeira etapa: apresentação da proposta de trabalho para os acadêmicos indicando o tema do estudo - numeração (IR) - e estabelecendo, através de uma mesa redonda, os tópicos de história que seriam investigados. Como os alunos haviam cursado a disciplina de História da Matemática no terceiro ano do curso, foi possível determinar os seguintes fatos relacionados ao contexto da numeração para a investigação:

- Problema dos segmentos incomensuráveis com os Pitagóricos e a diagonal de um quadrado;

- Solução do problema da incomensurabilidade apresentado por Eudoxo;

- O corpo ordenado dos racionais, o valor raiz quadrada de dois e os Cortes de Dedekind. 
Segunda etapa: realizar a brincadeira do "jogo-rápido", ou seja, dada uma palavra associar de forma instantânea outra palavra que lhe vem à mente.

Terceira etapa: responder por escrito a uma questão avaliativa, de forma individual, à saber: "Defina o que é a propriedade da completeza e o que isto representa no conjunto dos reais?"

\subsection{A investigação}

Os acadêmicos mostraram-se bastante motivados com a atividade. A turma era composta por nove alunos que foram divididos em três grupos que ficaram responsáveis pelo estudo e compreensão de cada tema, pela elaboração de material escrito para ser disponibilizado para o restante da turma e pela explanação do conteúdo. A maioria se envolveu com a tarefa e a participação foi coesa em todas as apresentações sendo que, no geral, não se restringiram à sua atribuição específica. Isso apontou certa maturidade investigativa por parte dos estudantes que estavam cientes da necessidade de assimilação de todos os tópicos elencados para obterem o melhor entendimento dos números reais e suas propriedades. Ademais, "todos os alunos precisam se exercitar na tarefa de transmitir ideias e se ajudar, mesmo que se priorize não o conteúdo, mas os exercícios de clareza da transmissão" (ANTUNES, 2007, p. 23), ou seja, o trabalho colaborativo contribui significativamente para a formação do profissional, até porque o professor tem entre suas tarefas a incumbência de transmitir uma ideia, favorecer o aprendizado e, para isto, a cooperação no ato de ensinar e aprender é fundamental.

Há de se salientar que, a partir dos assuntos de história arrolados anteriormente, as discussões estabelecidas durante as apresentações dos trabalhos conduziram ao estudo dos seguintes assuntos: números naturais, fracionários, inteiros; segmentos comensuráveis, incomensuráveis e o problema da diagonal de um quadrado; os números racionais e a estrutura de corpo ordenado; a existência de raiz quadrada de dois e os números irracionais; dízimas exatas, periódicas e não periódicas e suas relações com os racionais e irracionais; a propriedade da completeza, conjuntos enumeráveis e não-enumeráveis e conjunto denso.

O objetivo dessa etapa era fazer com que os alunos percebessem a distinção entre os números racionais e os números irracionais via segmentos incomensuráveis e, posteriormente, estabelecessem um paralelo entre a teoria de Eudoxo e a de Dedekind, com o propósito de melhor compreender a "completude" dos reais.

Quando questionados sobre como foi realizar a investigação e se ela auxiliou na compreensão do conjunto dos reais, os acadêmicos afirmaram que sim, ou seja, que auxiliou nessa formalização e que também já haviam tido contado com alguns destes fatos durante o curso - na disciplina de História da Matemática, como mencionado anteriormente - e a pesquisa acabou por ampliar tais conhecimentos.

Nas discussões percebeu-se que eles obtiveram uma compreensão clara dos conceitos de segmentos comensuráveis e incomensuráveis e da estratégia do Eudoxo para "contornar" este 
problema, entretanto transpareceu que eles não conseguiram realizar as devidas associações com os números irracionais enquanto numeração/conjunto. Pareceu que a noção ficou distante, ou seja, pensar nos reais como uma reta real completa lhes fazia sentido, mas pensar nos reais como um conjunto de elementos que obedecem a certas regras (corpo ordenado completo) não estava totalmente claro.

Quando questionados sobre seu entendimento da propriedade da completeza dos reais faziam referências a "reta sem buracos", "sempre que pinçamos uma reta encontramos um ponto", "não sobram espaços". Não foram feitas menções sobre o conjunto numérico, apesar da breve investigação realizada sobre o trabalho de Richard Dedekind (1831 - 1916).

Vê-se com isto, que o apego ao referencial geométrico é muito forte, porém insuficiente para uma completa formalização dos resultados no curso de Análise Real, que trabalha com as questões de aritmetização, tal como se observa no texto a seguir:

Weierstrass defendeu um programa no qual o próprio sistema dos números reais, antes de mais nada, fosse tornado rigoroso para que assim tudo que dele decorresse na análise inspirasse segurança. Esse notável programa, conhecido como aritmetização da análise, revelou-se difícil e intrincado, mas acabou se concretizando através de Weierstrass e seus seguidores, e hoje a análise pode ser deduzida logicamente de um conjunto de postulados que caracterizam o sistema dos números reais (EVES, 2004, p. 611, grifo do autor).

Com relação a investigação do trabalho sobre os Cortes de Dedekind, relacionado a axiomatização dos reais, os alunos mencionaram não terem compreendido a técnica que ele utilizou para "estender" o conjunto numérico dos racionais através dos cortes. Isto, de certo modo, já era esperado, pois uma compreensão exata da questão conduz a própria axiomatização dos reais, tarefa nada trivial. Esta falta de entendimento também justifica as dificuldades que eles apresentaram quando se estabeleceu o conjunto dos reais como uma coleção qualquer de elementos que obedecem a certas regras, ou seja, como corpo ordenado completo.

Depois de finalizada esta primeira etapa; isto é, concluídas as discussões sobre estas investigações históricas e, também, tendo os alunos já conhecimento das propriedades do corpo ordenado completo dos reais, com conhecimento das definições de ínfimo e supremo, inclusive com a apresentação do postulado da completeza ${ }^{2}$, passou-se para a segunda etapa. Assim, foi solicitado que associassem uma única palavra ao vocábulo "completeza"; ou seja, que dissessem que palavra que lhes vinha à mente quanto mencionado a "completeza" dos números reais.

Essa etapa foi pensada como uma forma divertida de introduzir novas discussões a respeito da numeração após todos os grupos terem exposto os seus trabalhos, buscando um modo de avaliar o nível de compreensão adquirido pelos participantes.

As respostas obtidas foram interessantes, porém não muito esclarecedoras, citaram: complicado, completo, buraco, reta, bijeção, íntegro, infinito e associações. Como se tratou

${ }^{2}$ Postulado da Completeza (ou Postulado de Dedekind): "Um corpo ordenado K chama-se completo quando todo subconjunto não-vazio, limitado superiormente, X contido em K, possui supremo em K" (LIMA, 2000, p. 64) 
de um "jogo rápido" a coação para finalizar a tarefa pode justificar a falta de coerência de algumas respostas com o solicitado, porém percebe-se a imprecisão de certos verbetes como íntegro, infinito e associações.

Como em nenhum momento os alunos fizeram menção aos irracionais, termo que se esperava ouvir entre as respostas, uma vez que são estes números que realizam o "preenchimento" da reta quando da existência dos racionais, a mesma atribuição foi solicitada novamente, mas agora como tarefa para ser entregue numa próxima aula. Novamente os alunos trouxeram expressões que não condizem com a completeza, a saber: denso, arquimediano, ordenado e crasso. A palavra "denso" foi repetidas vezes mencionada, possivelmente pelo fato da definição formal de conjunto denso ${ }^{3}$ ter sido trabalhada em aulas anteriores quando se discutia o que daria "o peso" da reta, no sentido de identificar os tipos de infinito (conjuntos enumeráveis e não enumeráveis - teoria de Cantor) e a localização destes objetos na reta. Vê-se, contudo, que este conceito não ficou claro para os alunos.

Quando informados sobre a expressão associada à completeza que se esperava que eles tivessem mencionado, que era irracional, os alunos concordaram com a associação, mas não souberam justificar o porquê do uso dos outros termos.

Aqui cabe uma reflexão sobre este processo formativo em detrimento do que muitos livros de Análise apresentam no seu escopo em relação aos reais, os quais são tomados de forma axiomatizada. Evidentemente esta postura acaba tendo que ser efetivada uma vez que não se teria como estabelecer a construção do conjunto dos números reais num curso de Análise, entretanto, o que se censura é a adoção única deste postulado como forma de introduzir os conteúdos da disciplina de Análise, visto que a experiência mostra que muitos acadêmicos ingressam no curso de Matemática com dificuldades em relação a numeração e estas, muitas vezes, não são exauridas durante o curso. Assim, devido à importância já mencionada deste conjunto numérico, a disciplina em questão do quarto ano mostra-se como uma das últimas oportunidades, no processo de formação inicial, para que os alunos possam produzir significados matemáticos condizentes com relação à numeração.

Ademais, ficou claro no decorrer da investigação que se os reais fossem apresentados somente através de postulado algumas dificuldades a respeito da numeração não seriam externadas e, também, não se oportunizaria para os alunos trabalharem com os elementos da reta e com suas particularidades. Ainda, no decorrer das apresentações, o revisitar à história destes pontos de complexidade do sistema numérico trouxe à tona as tribulações dos próprios acadêmicos, como exemplo: descrever uma dízima periódica como um número racional (fração) através da convergência de séries geométricas, explicar, de forma simétrica, porque toda fração (não inteira) pode ser representada como uma dízima periódica ou um decimal, justificar de forma coerente uma aproximação sequencial racional para um número irracional e estabelecer a ligação da convergência desta sequência com a propriedade da completeza (particularmente

\footnotetext{
${ }^{3}$ Definição: "Um conjunto X contido em IR chama-se denso em IR quando todo intervalo aberto $(a, b)$ contém algum ponto de X" (LIMA, 2000, p. 66). Observa-se que esta caracterização de conjunto denso está relacionada a disposição de seus elementos na reta e não, necessariamente, a sua quantidade visto que, por exemplo, os naturais e os racionais estão em correspondência biunívoca, mas os racionais são densos em $I R$ e os naturais não são densos em $I R$.
} 
para o raiz quadrada de dois) e, ainda, compreender como a relação de ordem de um conjunto acarreta as propriedades das relações de desigualdade.

Como os alunos ainda manifestavam dúvidas com relação a propriedade da completeza, tendo em vista as palavras obtidas com a atividade dois, alterou-se a sequência de ações, pois entende-se que o pesquisador pode interferir nas etapas do projeto quando julgar que tal atitude beneficiará o grupo como resposta às demandas obtidas no decorrer da própria investigação, uma vez que "pode-se dizer que a pesquisa-ação sempre implica em um plano de ação baseados em objetivos de mudança (melhora), a implementação e controle deste plano através de fases de ação, assim como a descrição concomitante do processo cíclico resultante". (MOREIRA, 2011, p. 93).

Dessa forma, no intuito de melhor entender o que os acadêmicos estavam pensando a respeito da propriedade da completude - e na expectativa de que assimilassem tal conceito, foi solicitado aos mesmos que apresentassem para a turma, e por escrito, as demonstrações do Teorema de Tales e da Proposição VI do Livro I de Os Elementos, de Euclides, apresentada no livro de Eves (2004, p. 176) ${ }^{4}$. Apesar de não fazerem parte do rol de conteúdos de Análise Real propriamente dito foram escolhidos tais temas, pois eles oferecem a oportunidade de pensar sobre a comensurabilidade e os números irracionais, em especial, o último aborda aspectos, em sua demonstração, da matemática pitagórica, pós-eudoxiana e moderna, sendo que esta última faz referência ao uso de limite 5 . De forma semelhante, o Teorema de Tales requer averiguações sobre as questões de comensurabilidade. Com isto pretendia-se que os alunos alcançassem outro nível de interpretação para estes conceitos, superando quaisquer dificuldades com relação a completude dos reais.

Durante a atividade, alguns acadêmicos não compreenderam a argumentação da demonstração do teorema de Tales no que diz respeito aos segmentos incomensuráveis e, a partir disto, retomou-se alguns pontos, utilizando o quadro para o esclarecimento das dúvidas.

Decorrido um tempo, a pergunta da terceira etapa foi incluída na primeira avaliação escrita que a turma realizou, para investigar o nível de compreensão adquirido pelos acadêmicos e para que eles pudessem fazer uma síntese dos pensamentos até então trabalhados. Dessa forma, solicitou-se: "Defina o que é a propriedade/postulado da completeza e o que isto representa no conjunto dos reais". De fato, a completeza está relacionada a existência de supremo, como já formalizada acima, e as caracterizações dos reais com relação a esta propriedade significa que para estes números toda sequência, que converge, tem limite em IR. Neste sentido, os irracionais completam os reais em relação aos racionais.

Dos nove alunos, dois não compareceram e um não respondeu à questão. As respostas obtidas estão transcritas abaixo, identificando os acadêmicos de $\mathbf{A}$ à $\mathbf{F}$.

\section{A: Podemos dizer que a propriedade da completeza nos garante que para qualquer}

\footnotetext{
${ }^{4}$ Proposição: áreas de triângulos que têm mesma altura estão entre si como suas bases.

5 "O fato de que qualquer número irracional pode ser considerado como o limite de uma sequência de números racionais, foi desenvolvido rigorosamente nos tempos modernos por George Cantor” (EVES, 2004, p. 177).
} 
ponto da reta que se pegue encontramos um número pertencente aos reais correspondente, ou seja, a reta dos reais não possui "buracos".

$\forall x_{0} \in X \subset I R$ teremos que se $x_{0}$ for a menor das cotas superiores então ele será o supremo do subconjunto $\mathrm{X}$.

$\forall x_{0} \in X \subset I R$ teremos que se $x_{0}$ for a maior das cotas inferiores então ele será o ínfimo do subconjunto $\mathrm{X}$.

B: A propriedade da completeza representa o total, ou seja, operar com clareza, corpo ordenado; sendo essas operações com números reais e irracionais.

C: Postulado de Dedekind:

Se um conjunto é limitado superiormente, então possui supremo.

Se um conjunto é limitado inferiormente, então possui ínfimo.

O postulado de Dedekind foi um grande auxílio para poder se definir precisamente o conjunto dos números reais, que até então, não era um conceito muito formalizado, introduzindo os chamados cortes de Dedekind.

D: Munida de todas as operações: associativa, comutativa, neutro, inverso, ..., vindo para completar os números reais, com o conjunto dos irracionais, fechando assim os "buracos" existentes na Reta Real até então.

E: Todo conjunto numérico $X \subset I R$ não é limitado superiormente.

Todo conjunto numérico $X \subset I R$ não é limitado inferiormente.

Ou seja, o conjunto dos números não é limitado, ele não é limitado.

F: Os reais são completos por causa dos irracionais.

Nem todas as respostas apresentaram a síntese desejada, sendo que o aluno $\mathbf{E}$ não alcançou os objetivos desta atividade, pois utilizou a definição de conjunto limitado de forma totalmente equivocada com relação ao solicitado.

As demais respostas, apesar de não explicitarem de forma exata a definição da propriedade da completeza, sempre fizeram menção a características que conduzem a um entendimento correto sobre o tema. $\mathrm{O}$ acadêmico $\mathbf{A}$ mencionou a questão do fechamento da reta - a reta dos reais não possui "buracos" - e relacionou conjuntos limitados e supremo com a propriedade da completeza; B fez menção a necessidade de operações e boa ordenação enfatizando os irracionais, ou seja, é possível inferir que $\mathbf{B}$ acredita que se faz necessário estender o corpo dos racionais para se conseguir a completude; o aluno $\mathbf{C}$, apesar de não enfatizar a ordenação do conjunto, detalhou a propriedade da completeza (postulado de Dedekind), mas acabou não conseguindo expressar suas ideias de forma clara ao relacionar o postulado com a técnica utilizada por Dedekind para construir o conjunto dos reais, os chamados Cortes de Dedekind; D menciona as operações (de corpo) e o 'fechamento' da reta com os irracionais, mas não enfoca a questão da ordenação e, por fim, $\mathbf{F}$ somente enfatiza os irracionais.

Observa-se, nas narrativas antecedentes, que a maioria associa de forma correta os irracionais ao fechamento, talvez pela atividade da etapa dois, mas deixam de abordar outros aspectos significativos desta teoria como a questão da ordenação. 


\section{CONCLUSÃO}

Os resultados desta investigação indicaram que o uso da História da Matemática como recurso didático foi uma estratégia bem-sucedida, pois permitiu realizar incursões as especificidades de propriedades e características dos números reais que as apresentações lineares dos cursos de Análise dificilmente i riam a bordar. A ssim, é p ossível a firmar que es te es tudo histórico diminuiu tais lacunas e conduziu os acadêmicos a compreensões mais profundas sobre numeração.

Ademais, a própria disciplina de Análise Real ganhou outro nível de significação na grade curricular, pois deixou de ser a disciplina que reprova para ser a disciplina que explica, detalha, formaliza a Matemática para se obter um melhor entendimento, mesmo que este não seja alcançado de forma imediata.

Essa mudança de percepção foi muito benéfica e os alunos passaram a valorizar mais as estruturas matemáticas e o cuidado que se deve ter ao utilizá-las, principalmente em tratando-se de futuros professores.

Ainda, oportunizar aos acadêmicos atividades que os coloquem no centro de sua formação, permitindo que já durante o seu processo formativo eles trabalhem de forma autônoma, vivenciando a pesquisa, o redescobrir do conhecimento, visualizando o conteúdo matemático como um produto do pensar através de incursões históricas é salutar para a sua formação.

A universidade deve promover a formação de um professor que desenvolva suas habilidades [...] Há necessidade, portanto, de um estímulo ao ato de aprender a aprender, no qual a prática da pesquisa se mostra um princípio norteador do ato cognitivo de pensar (MENDES, 2015, p. 108).

O texto Baroni e Nobre (1999) também informa que o uso da pesquisa histórica ligada a formação matemática do acadêmico auxilia

tanto o professor universitário quanto ao aluno de graduação. De posse desse material, o professor universitário pode tomar conhecimento da história minuciosa de determinados conteúdos que ele leciona, o que pode até levar a um aprimoramento na forma de transmissão de tais conteúdos. Para o aluno, o conhecimento da história dos conteúdos pode contribuir para uma melhor compreensão dos mesmos (p. 134).

Por outro lado, há de se salientar que tal sucesso investigativo poderia não ser alcançado se ao invés da numeração fosse escolhido outro tópico de estudo. Há de se levar em consideração o tema que se deseja abordar e o próprio desenvolvimento histórico do conteúdo. Para tanto, mais do que propor um projeto para os acadêmicos é preciso que o docente reconheça o próprio trajeto histórico do tema, investigando se este irá contribuir para o ensino, levando-se em consideração o tempo empregado para tal tarefa, a disponibilidade de material e a capacidade dos alunos compreenderem a linguagem aí descrita num fragmento da História. Baroni e Nobre 
(1999, p. 134) já citaram estes desafios: “o tema A Utilização da História da Matemática como Recurso Pedagógico é mais delicado e possui maior dificuldade de viabilização". Ainda, Miguel e Miorim (2004, p. 62-63) apresentam argumentos questionadores para o uso da História como ferramenta didática, apontando a falta de literatura adequada, os fatores complicadores da própria História e a forma de se trabalhar com fatos estanques, ou seja, com uma história cronológica descontextualizada, como empecilhos para o uso da História como ferramenta didática.

Contudo, tais dificuldades não precisam cercear um trabalho, mas, ao contrário, podem servir de estímulo para novas investigações. Requer-se, entretanto, a depender do tema que se deseja abordar, um trabalho preparatório mais detalhado onde o docente analise os materiais disponíveis e se a linguagem é adequada para a ação. Claro que todo estudo investigativo é benéfico, mas cabe levar em consideração se uma abordagem histórica é a mais adequada para a aquisição de um conceito, pois se hoje trabalha-se com determinadas sequências de conteúdos, que historicamente podem não coincidir, é porque se percebeu que este desencadeamento lógico funciona (!?). O que é inquietante: Este é o melhor, mais adequado?

Na tentativa de dirimir tais dificuldades, Mendes (2009, p. 100-104) apresenta orientações para elaboração de um trabalho de investigação em sala de aula que faz uso da História da Matemática, salientando o cuidado com a escolha do tema, com o nível de orientação a ser encaminhado, bem como orientando sobre as fontes que serão utilizadas na pesquisa, reforçando a importância deste poderoso recurso.

Conclui-se, contudo, que a metodologia empregada auxiliou na compreensão do conjunto dos números reais e de suas propriedades, fundamentando de forma adequada as primeiras demonstrações de Análise e, por consequência, as demais. Além disso, formar profissionais críticos, capazes de interferir de forma positiva e harmoniosa frente as diversas situações favoráveis ou conflitantes que a sala de aula pode apresentar é também um desafio para os docentes. Assim, propor atividades de pesquisa nas quais o aluno atue como ator principal deve ser uma prática a ser incorporada nas licenciaturas, pois conduz os acadêmicos a se posicionar, defender ideias, atitudes, discutir, refletir, produzir. 


\section{REFERÊNCIAS}

ANTUNES, C. Diário de um Educador. Campinas: Papirus, 2007.

BARONI, R. L. S.; OTERO-GARCIA, S. C. Análise Matemática no Século XIX. Campinas: SBHMAT, 2013.

EVES, H. Introdução à história da matemática. Tradução: Hygino H. Domingues. Campinas: Editora da UNICAMP, 2004.

FIORENTINI, D.; LORENZATO, S. Investigação em educação matemática: percursos teóricos e metodológicos. Campinas: Autores associados, 2006.

HAIRER, E.; WANNER, G. Analysis by Its History. [S.1.]: Springer, 2008.

KATZ, V. J. História da Matemática. Lisboa: Fundação Calouste Gulbenkian, 2010.

LIMA, E. L. Curso de análise. Rio de Janeiro: Instituto de Matemática Pura e Aplicada, 2000. v. 1 .

LUDKE, M.; ANDRÉ, M. E. D. A. Pesquisa em educação matemática: abordagens qualitativas. São Paulo: EPU, 1986.

MEDEIROS, E. A. de; AMORIM, G. C. C. Análise textual discursiva: dispositivo analítico de dados qualitativos para a pesquisa em educação. Laplage em revista, v. 3, n. 3, p. 247-260, 2017.

MENDES, I. A. Investigação histórica no ensino da matemática. Rio de Janeiro: Ciência Moderna, 2009.

MENDES, I. A. História da Matemática no Ensino: entre trajetórias profissionais, epistemologias e pesquisas. São Paulo: Livraria da Física, 2015.

MIGUEL, A.; MIORIM, M. Â. História na Educação Matemática: propostas e desafios. Belo Horizonte: Autêntica, 2004.

MORAES, R.; GALIAZZI, M. do C. Análise textual discursiva: processo reconstrutivo de múltiplas faces. Ciência \& Educação, v. 12, n. 1, p. 117-128, 2006.

MOREIRA, M. A. Metodologias de pesquisa em ensino. São Paulo: Livraria da Física, 2011. PIMENTA, S. G.; ANASTASIOU, L. das G. C. Docência no ensino superior. 5. ed. São Paulo: Cortez, 2014.

THIOLlenT, M. Metodologia da Pesquisa-Ação. São Paulo: Cortez, 1985. 